\title{
Research on a New Smart Methane \& Solar Hybrid Power Generating System
}

\author{
Yongrui Li \\ North China Electric Power University (Baoding), Baoding, Hebei, China \\ BHLTLYR@126.com
}

\begin{abstract}
Keywords: New energy; Photovoltaic generation; Marsh gas power generation; Hybrid power system
\end{abstract}

\begin{abstract}
The intent of this paper is to study a new smart methane \& solar hybrid power generating system. The structure composition of new smart generating system is firstly introduced. Secondly, the function of each part is analyzed. Then, the principle of new smart generating system is presented. Finally, this paper shows the application effect of the system with an example. The good running performance of this application has been verified by the practice. The system provided on this paper can be offered as a reference for design of small power generation device.
\end{abstract}

\section{Introduction}

With the high-speed development of society, global environmental deterioration and the shortage of energy have become increasingly prominent. Development and utilization of new energy and actively seeking new energy-saving technology are effective means of dealing with the energy crisis and environmental stress [1]. Solar electrical energy generation and biogas power generation show promise.

However, solar electrical energy generation and biogas power generation have their own advantage and disadvantage. The power generation is in an unstable and unsustainable state when they work alone [2-7]. So, developing a system that can complement advantages each other and provides continuous and stable energy is of great significance.

This paper provides a new smart methane \& solar hybrid power generating system. In this system, the solar power system and the marsh gas generating set are connected with controller and other devices. With the control of the controller, the above problems will be solved.

\section{Solar Electrical Energy Generation and Methane Power Generation}

Solar electrical energy generation is a technology that can convert solar energy into electrical energy. Methane power generation is one of sustainable power generation technology [8-10]. Methane power generation use a large number of organic wastes (for example lees liquid, livestock manure, urban garbage and sewage) of industrial, agricultural or urban life. The biogas produced by anaerobic fermentation processing can drive biogas power generation unit.

\section{The Structure Composition of the New Smart Methane \& Solar Hybrid Power Generating System}

A new smart methane \& solar hybrid power generating system includes methane electric power set, solar array, intellectual control charger, a storage battery, an inverter and a controller. The methane electric power set is respectively connected with the load and the controller. The solar energy cell is connected with the controller. The controller connected with the intelligent charger, storage battery, electronic inverter and the load in turn. The relationship between each part is shown in Fig. 1. 


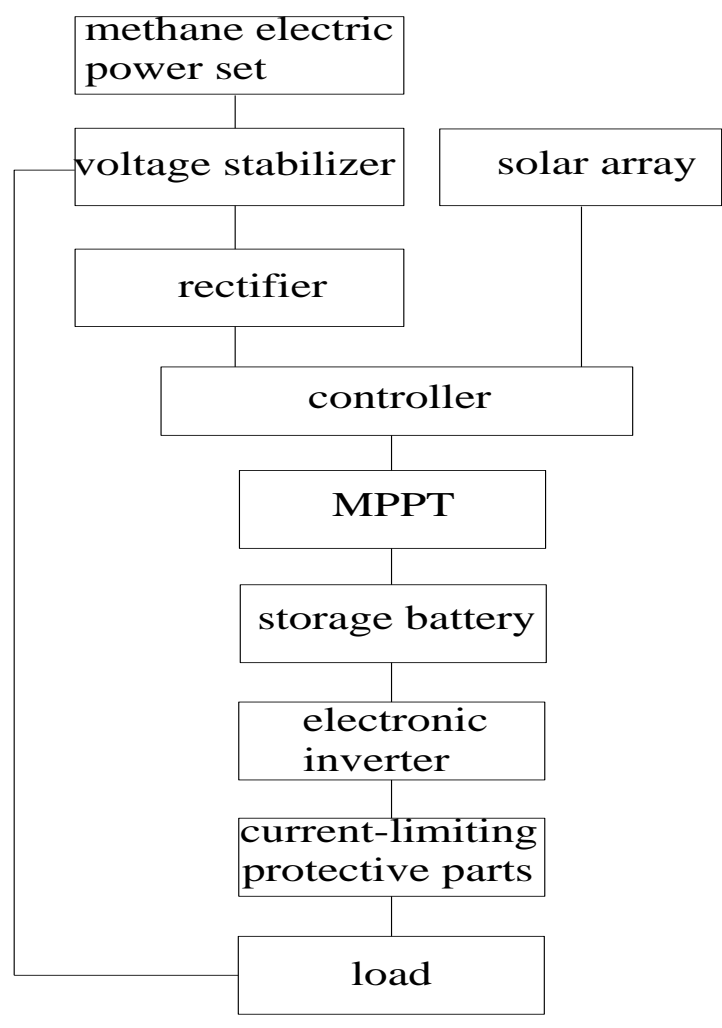

Figure 1. The relationship between each part

\section{The Function of Each Part}

Methane electric power set can provide the rated power output of $50-60 \mathrm{~Hz}, 1800 \mathrm{~W}, \mathrm{AC} 220 \mathrm{~V}$. The continuous working time is 10 hours. The device is started manually and stops working automatically after 10 hours of operation.

Voltage stabilizer regulates 220 volt alternating currents provided by methane electric power set into $50 \mathrm{~Hz}$ sine wave AC220V and outputs it.

Rectifier adjusts the output voltage of voltage stabilizer into 14.4DC.

The solar array is consisted of two solar panels together in parallel and output 18VDC power.

MPPT can intelligently identify battery storage state and has a charging protection function.

$100 \mathrm{AH}$ lead-acid battery outputs $12 \mathrm{vdc}$ and can store the excess power, so it can be used as a standby power supply.

Electronic inverter can provide the power of AC220, 50HZ to the load.

A $10 \mathrm{~V}$ amperite is put at the output of deceive. When the user electrical overloads or short circuits, current limiter can be automatically disconnected to protect the equipment.

The functions of each part of the controller are as follows:

A set of $\mathrm{C}$ language program is input into the controller. The voltage of voltage sensor can be input directly into the STM32 microcontroller IO port. After reading the ad, the STM32 microcontroller compares the value with the threshold to judge the working state of solar array and the battery power. Whether the methane electric power set is working will also be judged. According to them, the on-off of the relay can be controlled.

The voltage sensor is used to collect the terminal voltage of the solar cell and the voltage of the voltage stabilizer. In addition, the electrical signal is transmitted to the microcontroller by it.

The partial pressure module uses $7 \mathrm{~V}$ voltage and provides $5 \mathrm{~V}$ voltage to microcontroller.

Controller battery output DC12V current to the relay. 
The system uses small signal current output by single chip microcomputer to control the relay's closing and opening, so as to control the switching on and switching off of the large current circuit of operating circuit.

\section{The Principle of New Smart Generating System}

The system use solar array and methane electric power set as power supply. After the electric power generated by methane electric is regulated by voltage stabilizer, a part of them directly supply load and the other part is used as one of the battery charging power supply. At this point, the sensor in controller will automatically capture the voltage of the solar battery and judge the working state of solar battery. If the solar battery voltage is above $16 \mathrm{~V}$, the program in the controller will automatically control the electric relay, so that the storage battery is charged by the solar array. If not, the biogas generator will charge the battery. When the whole equipment works, in order to protect the circuit, the charging switch will be turned off when the inverter supplies power to the load. In other words, the battery cannot charge and discharge at the same time.

\section{Application Effect of the New Smart Methane \& Solar Hybrid Power Generating System}

We have completed a material object with methane electric power set which can provide $2500 \mathrm{~W}$ of power, a 320W parallel solar array and a 100Ah lead acid battery. It is shown in Fig. 2. The system can output electric power of 50HZ AC220 and the maximum power of it is $2200 \mathrm{~W}$. The daily peak power of it is $52 \mathrm{~K} / \mathrm{H}$. The system can supply the electric power without a break in 24 hours. Technical parameters of methane electric power set are shown in Table 1. What's more, the power generated by system can meet the basic needs of electric power of a family. On the other hand, the way of generating power is free of contamination. As a clean energy, biogas can be made good use of by the system. In addition, the size of solar array can be adjusted by people according to the need. The users can also participate in the control and determine the time when the system supplies power and when the system is in charging state.

Table 1 Technical parameters of methane electric power

\begin{tabular}{cccccc}
\hline item & $\begin{array}{c}\text { Nominal } \\
\text { voltage }\end{array}$ & $\begin{array}{c}\text { rated } \\
\text { frequency }\end{array}$ & $\begin{array}{c}\text { rated } \\
\text { current }\end{array}$ & rated power & Dc output \\
\hline parameter & $230 \mathrm{~V}$ & $50 \mathrm{~Hz}$ & $7.0 \mathrm{~A}$ & $4.6 \mathrm{KW}$ & $12 \mathrm{~V}, 8 \mathrm{~A}$ \\
\hline
\end{tabular}

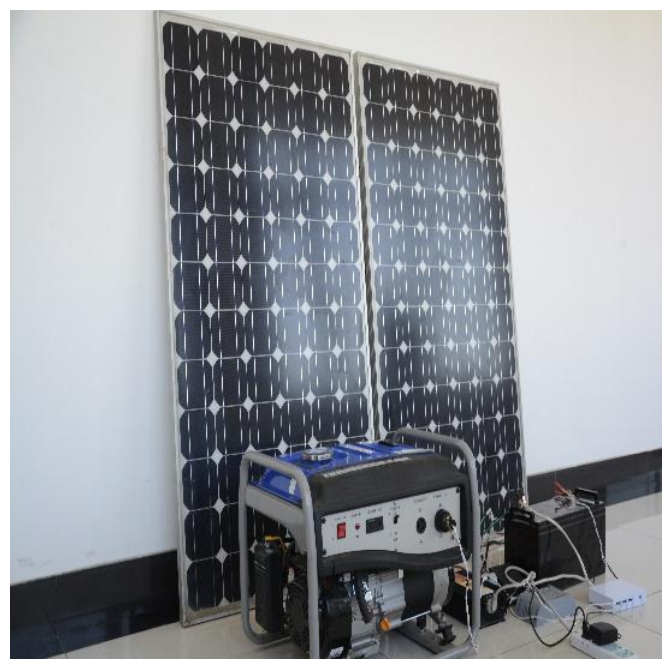

Figure 2. The product figure 


\section{Conclusion}

A new smart methane \& solar hybrid power generating system is provided in this paper. The structure composition of it, the function of each part, the principle of new smart generating system and application effect of the new smart methane \& solar hybrid power generating system are introduced in turn. The system has the function of real-time monitoring, intelligent judgment and automatic switching. Furthermore, the system can supply power uninterruptedly. It can not only be used as auxiliary power supply for power network, but also be used in farms and electricity rationing for remote areas.

\section{References}

[1] H.X. Wu: Research on flat plate type CPC solar thermoelectric power generation device(MS., South China University of Technology, China 2011),p1.(In Chinese)

[2] Cornforth, D.J., Berry, A.and Moore, T.: Power Electronics and ECCE Asia (ICPE \& ECCE)( May 30 2011-June 3 2011). vol., pp.2035-2042.

[3] Asaduz-Zaman, M., Chowdhury, A.H.,:Electrical Engineering and Information Communication Technology (ICEEICT)( 21-23 May 2015). vol., pp.1-6.

[4] Uriarte, F.M.; Smith, C.,VanBroekhoven, S.and Hebner, R.E.: Power Systems, IEEE Transactions (Nov. 2015)vol.30, pp.3209-3216.

[5] Rui Huang, Tiana Huang,Gadh, R.and Na Li: Smart Grid Communications (SmartGridComm) (5-8 Nov. 2012).vol., pp.528-533.

[6] Y.Y. Lin:Research on grid connected converter and DC microgrid control (MS.,Shangdong University, China 2011),p12.(In Chinese)

[7] Smee, C.S.W., Perm, I.and Nussey, P.F.: Power and Energy Engineering Conference (APPEEC) (15-18 Nov. 2015),vol., pp.1-4.

[8] G.K. Zeng,J. Xie and F. ying: Biogas power generation technology and its application status and prospect in China, Vol.2(2005) No.1,p.38. (In Chinese)

[9] V. R. Kolluru, K. Mahapatra and B. Subudhi:Advances in Electrical Engineering (ICAEE)( 2014), vol.pp. 1-6.

[10]S. Singh, R. Kumar and V. Vijay: Power India International Conference (PIICON), ( Delhi, 2014), vol.pp. 1-6. 